\title{
Numerical Study of Turbulent Pulsatile Blood Flow through Stenosed Artery Using Fluid-Solid Interaction
}

\author{
Mehdi Jahangiri, ${ }^{1}$ Mohsen Saghafian, ${ }^{1}$ and Mahmood Reza Sadeghi ${ }^{2}$ \\ ${ }^{1}$ Department of Mechanical Engineering, Isfahan University of Technology, Isfahan 8415683111, Iran \\ ${ }^{2}$ Department of Biomedical Engineering, University of Isfahan, Isfahan 8174673441, Iran \\ Correspondence should be addressed to Mehdi Jahangiri; m.jahangiri@me.iut.ac.ir
}

Received 4 November 2014; Accepted 24 March 2015

Academic Editor: Eduardo Soudah

Copyright (C) 2015 Mehdi Jahangiri et al. This is an open access article distributed under the Creative Commons Attribution License, which permits unrestricted use, distribution, and reproduction in any medium, provided the original work is properly cited.

\begin{abstract}
The turbulent pulsatile blood flow through stenosed arteries considering the elastic property of the wall is investigated numerically. During the numerical model validation both standard $k-\varepsilon$ model and RNG $K-\varepsilon$ model are used. Compared with the RNG $K-\varepsilon$ model, the standard $K-\varepsilon$ model shows better agreement with previous experimental results and is better able to show the reverse flow region. Also, compared with experimental data, the results show that, up to $70 \%$ stenosis, the flow is laminar and for $80 \%$ stenosis the flow becomes turbulent. Assuming laminar or turbulent flow and also rigid or elastic walls, the results are compared with each other. The investigation of time-averaged shear stress and the oscillatory shear index for $80 \%$ stenosis show that assuming laminar flow will cause more error than assuming a rigid wall. The results also show that, in turbulent flow compared with laminar flow, the importance of assuming a flexible artery wall is more than assuming a rigid artery wall.
\end{abstract}

\section{Introduction}

Atherosclerosis is a disease that is characterized by the formation of plaques that narrow the arterial lumen. The narrowing of the coronary arteries can stop the perfusion of blood to the lower parts of the myocardium and possibly lead to myocardial ischemia, myocardial infarction, and sudden cardiac death [1].

In the study of the causes and progression of this disease, in addition to conventional methods in the medicine for forecasting and evaluating the disease progress, computational fluid dynamics are used to examine the role of hemodynamics on the localization, development, and progression of atherosclerosis disease. Simultaneous with hemodynamic studies, some researchers have focused on modeling the arterial wall and have examined the relationship between arterial wall stress and vessel wall diseases [2-4].

Recently, researchers have paid great attention to the effect of fluid-solid interaction in biological systems, especially cardiovascular ones. They believe that the simultaneous solution of fluid-solid will greatly help in better understanding the pattern of arterial disease $[5,6]$.

For example, Bathe and Kamm [7] simulated the laminar pulsatile flow passing through a flexible artery with stenosis using ADINA Software. They considered stenoses of 51\% and $96 \%$ area reduction and evaluated and compared the pressure drop and circumferential stress across the artery at different times. They also studied the effect of Reynolds number on the pressure drop.

Tang et al. [8] numerically examined laminar flow in flexible carotid artery with symmetric stenosis using ADINA software. Their results showed that severe stenosis causes critical flow conditions such as negative pressure and high and low shear stress which may lead to artery compression, plaque rupture, platelet activation, and arterial thrombosis.

Although in such studies the flexibility of the artery wall has been considered, they have ignored the turbulence caused by stenosis. In fact, blood flow in arteries is usually laminar. However, a moderate or severe stenosis can cause turbulent flow in the vasculature [9]. A better understanding of the flow 
and flow turbulence in the poststenotic region can lead to more accurate diagnostic methods [10]. Turbulent blood flow due to arterial stenosis has long been investigated [11].

Many experimental studies have been conducted for studying a steady turbulent flow [12-14]. Deshpande and Giddens [13] studied the steady turbulent flow through a $75 \%$ stenosed tube at Reynolds numbers ranging from 5000 to 15000 by laser Doppler anemometer (LDA). Ahmed and Giddens [14] measured the steady velocity field in the presence of a symmetric stenosis with a rigid wall by the LDA. The range of the Reynolds number was 500-2000 in the upstream of the stenosis and stenoses of 25,50 , and $75 \%$ area reduction were studied.

Due to difficulties in performing experimental tests, there are only a few experimental studies for unsteady turbulent flow in the presence of stenosis.

Ahmed and Giddens [15] measured pulsating flow field in the presence of a symmetric stenosis by the LDA. They considered sinusoidal velocity profile, a Womersley number of 7.5 , stenoses of 25,50 , and $75 \%$ area reduction, and the average Reynolds number of 600 for testing.

These experimental studies showed that, even with a low percentage of stenosis, transient or turbulent flow may occur. The above experimental data were used for assessment of numerical methods for modeling of turbulent flow in internal flows. On the other hand since the turbulent flow calculations are difficult and time-consuming, there are very few computational studies on the turbulent pulsatile flow in the artery with a stenosis. For example, using the finite element software FIDAP, Ghalichi et al. [16] investigated transient and turbulent flow through $50 \%, 75 \%$, and $85 \%$ stenosed models over a Reynolds number range of 500 to 2000. Their results showed that the laminar flow model overestimates the vortex length when the flow becomes transitional or turbulent.

Banks and Bressloff [17] modeled pulsatile turbulent flow in the carotid bifurcation with a stenosis by a threedimensional model. FLUENT software was used for solving the set of governing equations. Three types of stenosis (mild, moderate, and severe) were considered, and the effect of turbulence intensity and turbulent viscosity on velocity profiles was studied.

Since wall elastic property and physiological pulses are not considered as boundary conditions in these studies, in the present study the turbulent blood flow through a stenotic artery model is numerically simulated considering fluidstructure interaction (FSI) using ADINA 8.8. At first the effect of turbulent blood flow on the variations of time-averaged shear stress and the oscillatory shear index for $80 \%$ stenosis is investigated. Then the obtained results are compared with the results of assuming laminar flow and rigid wall of coronary artery.

\section{Governing Equations}

2.1. Reynolds-Averaged Navier-Stokes Equations (RANS) [18]. In unsteady turbulent flows, if we consider each parameter as the sum of an average component and an oscillating component in the Navier-Stokes equation, then the RANS equations are obtained as follows:

$$
\begin{aligned}
& \frac{\partial \bar{u}_{i}}{\partial x_{i}}=0 \\
& \frac{D \bar{u}_{i}}{D t}=-\frac{1}{\rho} \frac{\partial \bar{P}}{\partial x_{i}}+\frac{\partial}{\partial x_{j}}\left(\frac{\mu+\mu_{T}}{\rho}\left(\frac{\partial \bar{u}_{i}}{\partial x_{j}}+\frac{\partial \bar{u}_{j}}{\partial x_{i}}\right)\right) .
\end{aligned}
$$

2.2. Turbulence Models [18]. To calculate $\mu_{T}$, this paper uses the two-equation turbulence $K-\varepsilon$ standard and $K-\varepsilon$ RNG models. In the turbulence flow, viscosity is defined as follows, where $\mu_{0}$ is laminar viscosity and $\mu_{T}$ is turbulence viscosity:

$$
\mu=\mu_{T}+\mu_{0}
$$

In $K-\varepsilon$ standard turbulence model, $\mu_{T}$ is calculated as follows:

$$
\mu_{T}=\rho c_{\mu} \frac{k^{2}}{\varepsilon}
$$

where $k$ is turbulence kinetic energy and $\varepsilon$ is turbulence dissipation rate.

\section{Numerical Validation}

To check the accuracy of our numerical solution, the numerical results of the present work are compared with the experimental results presented by Ahmed and Giddens [15] and the numerical results provided by the Banks and Bressloff [17] and Varghese and Frankel [19].

If we consider the origin of coordinates at the center of stenosis, the numerical results of the present work were compared with the experimental results presented by Ahmed and Giddens [15] and the numerical results provided by Banks and Bressloff [17] and Varghese and Frankel [19] at two different distances of stenosis downstream and in the time of maximum speed. The results of Figures 1 and 2 indicate a better agreement of numerical data of the present work with the results of Ahmed and Giddens [15] than the numerical results of Banks and Bressloff [17] and the numerical work of Varghese and Frankel [19].

The results indicate a higher consistency between the $K-\varepsilon$ standard model and experimental results. As a result, the $K-\varepsilon$ standard model was used in this study.

\section{Present Work and Numerical Methods Used}

In this study a model of coronary artery with a simple, symmetrical stenosis with flexible wall is considered. The computational domain and its dimensions are shown in Figure 3.

The geometry of stenosis is defined as follows [21]:

$$
\frac{R(z)}{R_{0}}=1-\left(\frac{R_{0}-R_{0, t}}{2 R_{0}}\right)\left(1+\cos \frac{2 \pi\left(z-z_{m}\right)}{L_{\mathrm{st}}}\right),
$$

where $R_{0}$ is the radius of the healthy artery, $R(z)$ is the artery radius in the stenosis region, $R_{0, t}$ is artery radius at the stenosis throat, $z_{m}$ is the location of the center of the stenosis, 


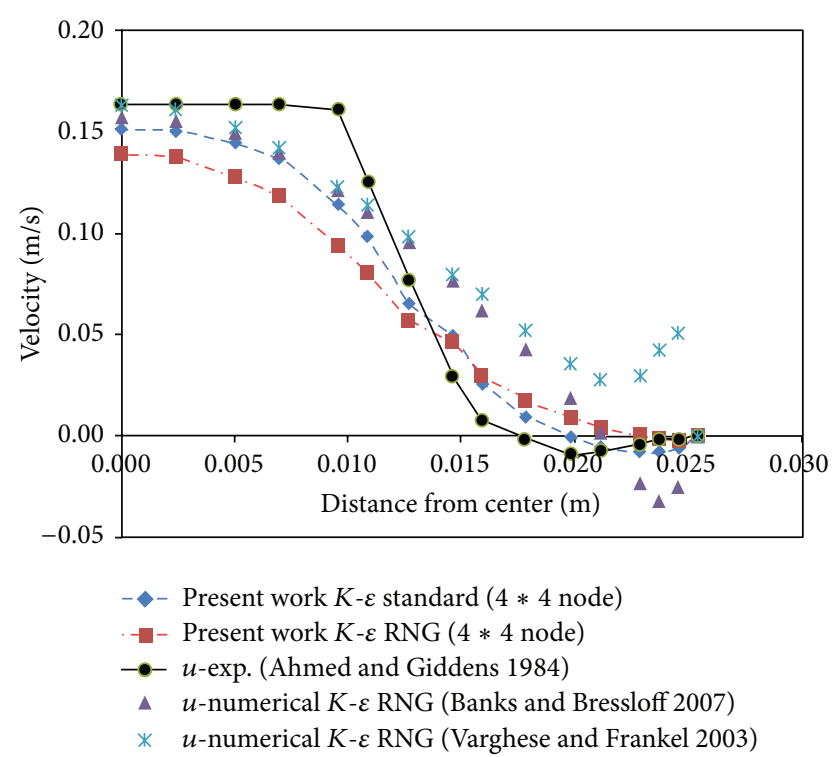

FIgURE 1: Velocity profile at distance $z=D$ from throat of stenosis.

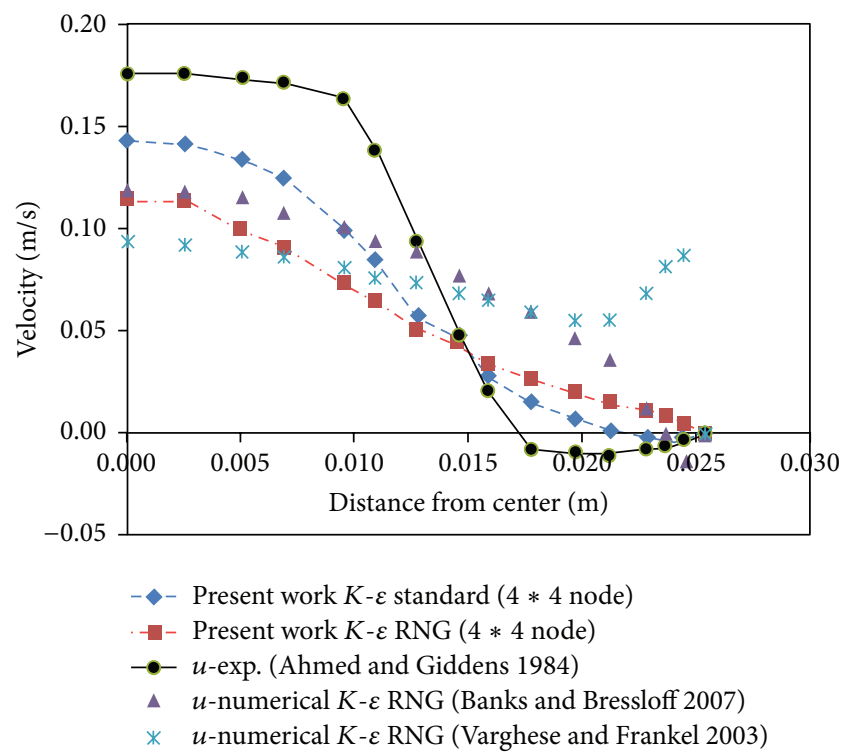

FIGURE 2: Velocity profile at distance $z=1.5 D$ from throat of stenosis.

and $L_{\mathrm{st}}$ is the length of stenosis. The characteristics of blood as a Newtonian, incompressible fluid and the characteristics of artery wall are given in Table 1 [21].

The pulsatile velocity profile of the right coronary artery was used as the inlet boundary condition [20]. Figure 4 shows the pulsatile velocity profile which is dimensionless by the period of pulsatile cycle, $t_{p}$, which is $0.8 \mathrm{~s}$.

The fluid-structure interaction (FSI) conditions were used in the common boundary of fluid and solid. The

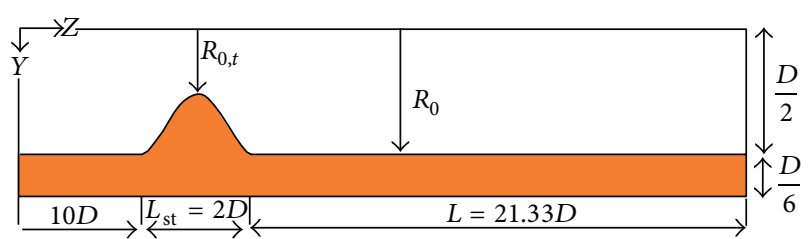

Figure 3: Computational domain.

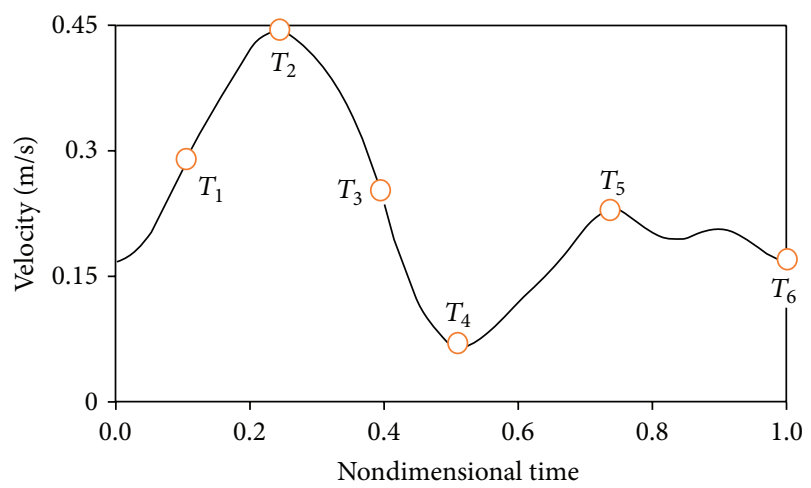

FIGURE 4: Inlet pulsatile velocity profile [20].

TABLE 1: Properties of fluid and artery wall.

\begin{tabular}{lc}
\hline Thickness of artery wall $(\mathrm{m})$ & 0.0005 \\
Elasticity modulus of the artery wall $(\mathrm{kPa})$ & 910 \\
Density of artery wall $\left(\mathrm{Kg} / \mathrm{m}^{3}\right)$ & 1300 \\
Poisson ratio of artery wall & 0.49 \\
Blood density $\left(\mathrm{Kg} / \mathrm{m}^{3}\right)$ & 1050 \\
Blood viscosity $(\mathrm{Pa} \cdot \mathrm{s})$ & 0.0033 \\
\hline
\end{tabular}

governing equations for the solid-fluid coupled problem are as follows [21]:

$$
\begin{aligned}
d_{f} & =d_{s}: \text { Displacement, } \\
n \cdot \sigma_{f} & =n \cdot \sigma_{s}: \text { Traction, } \\
\dot{d}_{f} & =\dot{d}_{s}: \text { No slip, }
\end{aligned}
$$

where $d, \sigma$, and $n$ are displacement, stress tensor, and normal vectors. The governing equations of the solid domain are as follows [21]:

$$
\rho_{s} \ddot{d}_{s}=\nabla_{\circ} \cdot \sigma_{s}+\rho_{s} f_{s},
$$

where $\rho_{s}$ is the wall density, $\sigma_{s}$ is the Cauchy stress tensor, $f_{s}$ is the body force vector, and $d_{s}$ is the wall displacement vector.

When studying the solid-fluid coupled problem, we should apply blood pressure pulse to the problem as the output condition. These pulses are obtained from experimental conditions and were shown in Figure 5 [21].

The axial velocity profiles at a distance of $1 \mathrm{D}$ from the stenosis throat in three types of meshing are shown in Figure 6. The results indicated that the results of $10200 \mathrm{com}$ putational cells and 15300 computational cells are consistent with each other. Thus, for reducing the computational time, 10200 computational cells will be used for calculations. 


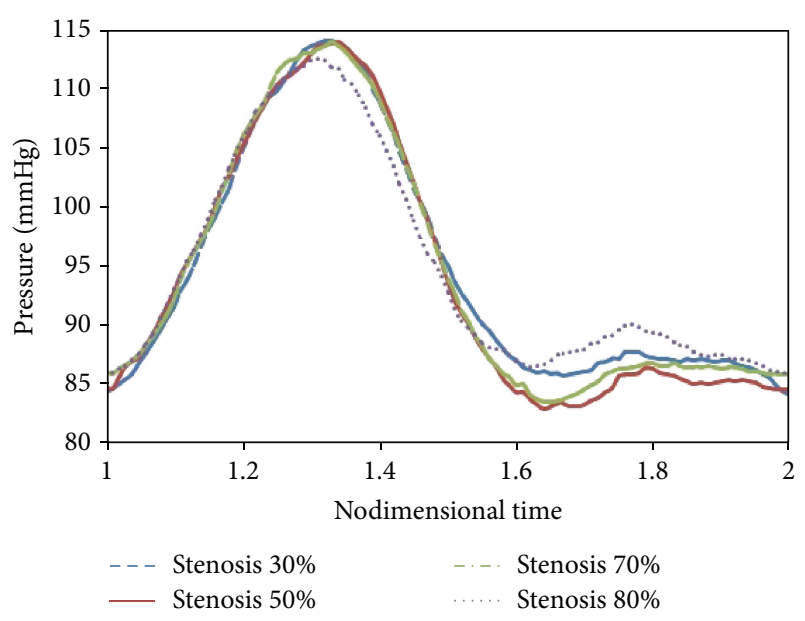

FIgURE 5: Outlet pressure pulse.

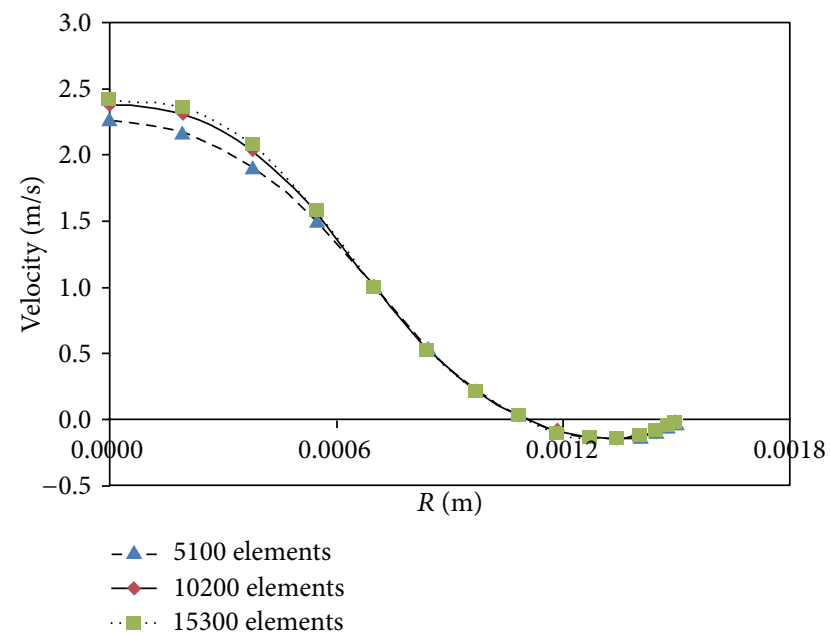

FIGURE 6: Results independency from grid of solution domain.

\section{Results}

Comparisons between the mean inlet pressure $\left(P_{1}\right)$ for stenosis percentages of $30 \%, 50 \%, 70 \%$, and $80 \%$ are given in Figure 7. As can be seen, up to $70 \%$ stenosis, there is a very good consistency between experimental results [21] and the laminar flow assumption which suggests that, up to $70 \%$ stenosis, the flow is laminar. Shifting from $70 \%$ to $80 \%$, the difference between experimental results and the laminar flow assumption increases, and there is a much higher consistency between experimental results and the turbulence flow assumption which suggests that, for $80 \%$ stenosis and higher, the flow is turbulent and the laminar flow assumption is not appropriate anymore. Mean inlet pressure for $80 \%$ stenosis in the case of laminar flow assumption is $102.4 \mathrm{mmHg}$, in the turbulent flow case is $105 \mathrm{mmHg}$, and in the experimental case is $104.8 \mathrm{mmHg}$. Given above, we select $80 \%$ stenosis and perform next calculations on it.

Figures 8 to 15 show the timed-averaged changes of shear stress and the oscillatory shear index in the axial

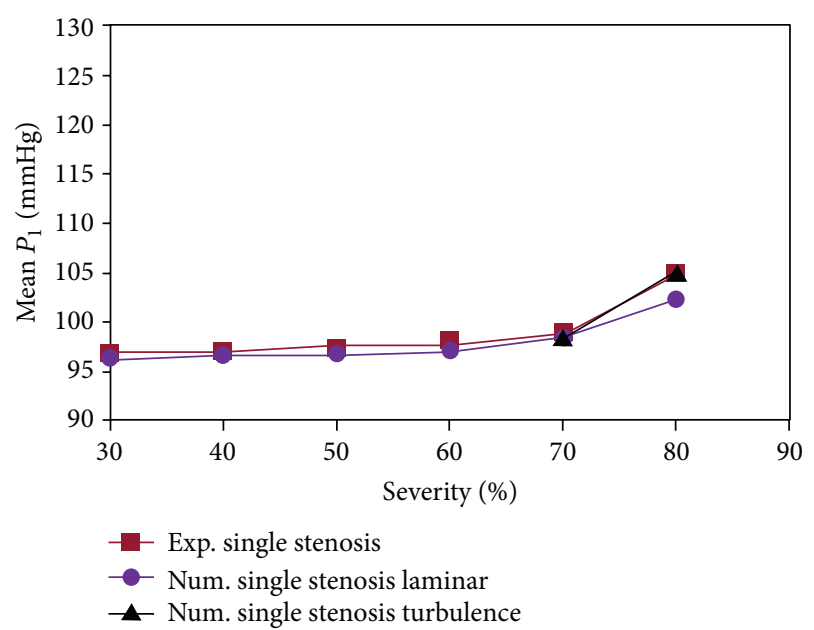

FIGURE 7: Comparisons between the inlet pressure.

direction for $80 \%$ stenosis for the laminar or turbulent flow assumption and the rigid or flexible wall assumption. The time-averaged shear stress and the oscillatory shear index are among hemodynamic parameters used for identifying areas prone to arteriosclerosis.

The oscillatory shear index (OSI) is a mechanical parameter for flow oscillation showing the deviation of the wall shear stress from the dominant direction of blood flow during the cardiac cycle. The OSI value ranges from zero (for no change in the direction of wall shear stress) to 0.5 (for a 180degree change in the direction of wall shear stress) [22]. To determine the OSI value, the following equation is used:

$$
\mathrm{OSI}=0.5 \times\left(1-\frac{\left|\int_{0}^{T} \tau_{w} d t\right|}{\int_{0}^{T}\left|\tau_{w}\right| d t}\right)
$$

Time-averaged shear rate is defined as follows:

$$
\text { Mean WSS }=\frac{1}{T} \int_{0}^{T} \tau_{w} d t .
$$

In the above equations, $T$ is the periodicity of the cardiac cycle and $\tau_{w}$ is the shear stress vector.

As is clear from Figures 8 to 11, by changing from the flexible-wall mode to the rigid-wall mode as well as from the laminar flow assumption to the turbulent flow assumption, the time-averaged shear stress slightly increases in the prestenotic area. At the proximal shoulder region, the time-averaged shear stress significantly increases and, at the distal shoulder and poststenotic region, the timeaveraged shear stress decreases further. This decrease in shear stress increases the production of reactive oxygen species and essentially increases the oxidation of LDLs in the intima. Oxidized LDLs stimulate endothelial cells to express leukocyte adhesion molecules such as vascular cell adhesion molecule-1 (VCAM-1) and intercellular adhesion molecule-1 (ICAM-1). Consequently, platelet adhesion to the endothelium and activation is possible, in an area where shear stress is low. Activated platelets release growth factors 


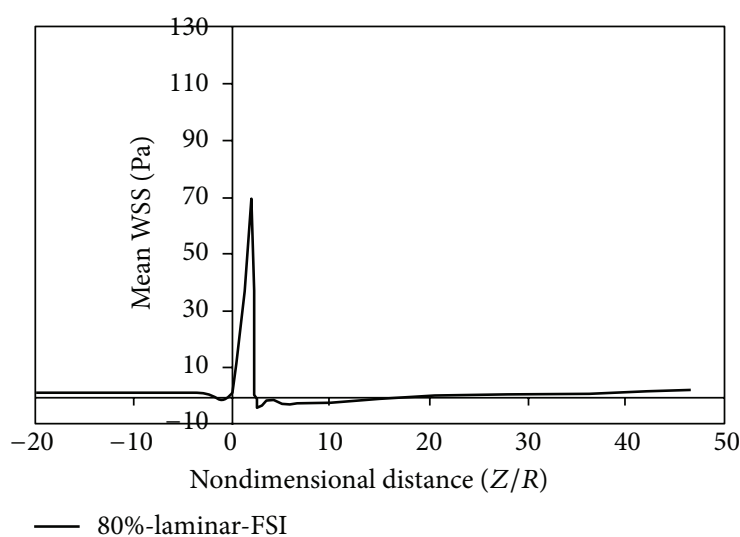

FIGURE 8: Mean WSS, laminar, flexible mode.

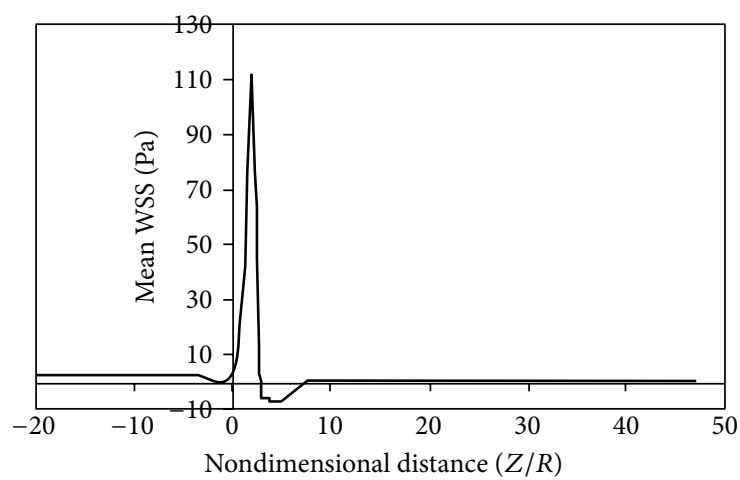

$80 \%$-turbulence-FSI

FIGURE 9: Mean WSS, turbulence, flexible mode.

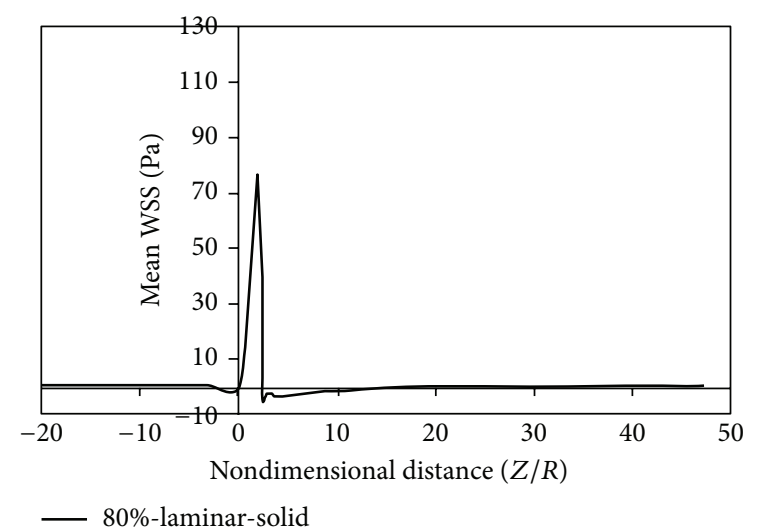

Figure 10: Mean WSS, laminar, and solid mode.

such as TGF- $\beta$. TGF- $\beta$ significantly enhances proliferation of smooth muscle cells [23]. Studies have also shown that activated platelets release MMP-2, which mediates further platelet aggregation [24]. Thus poststenotic area not only is prone to develop plaque and new plaque formation, but also is more prone to the development of thrombosis. Angiographic studies have shown that plaque development occurs more in the poststenotic area [25] and the number of smooth muscle cells in the distal shoulder is far more than the proximal [26].

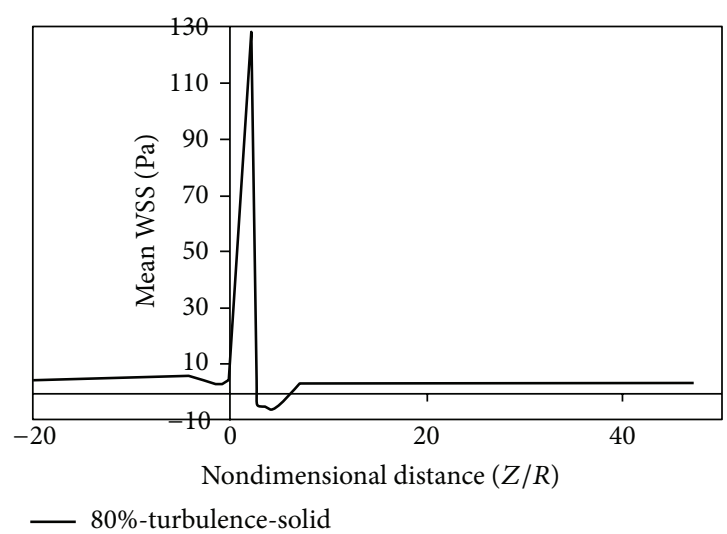

FIGURE 11: Mean WSS, turbulence, and solid mode.

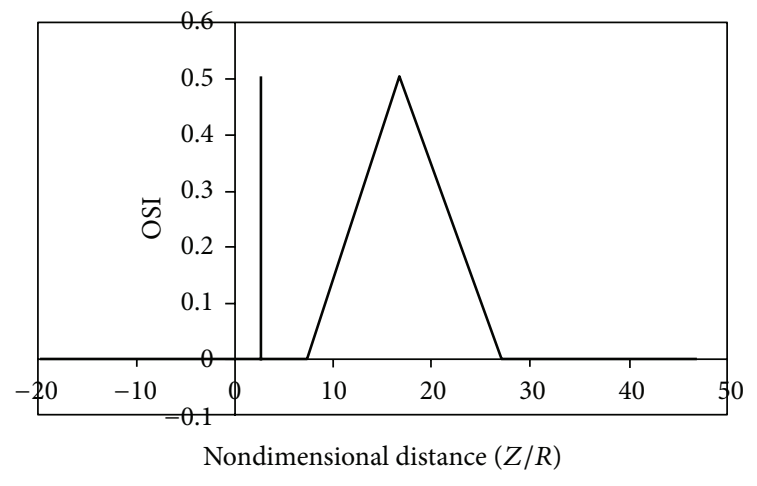

— $80 \%$-laminar-FSI

FIGURE 12: OSI, laminar, flexible mode.

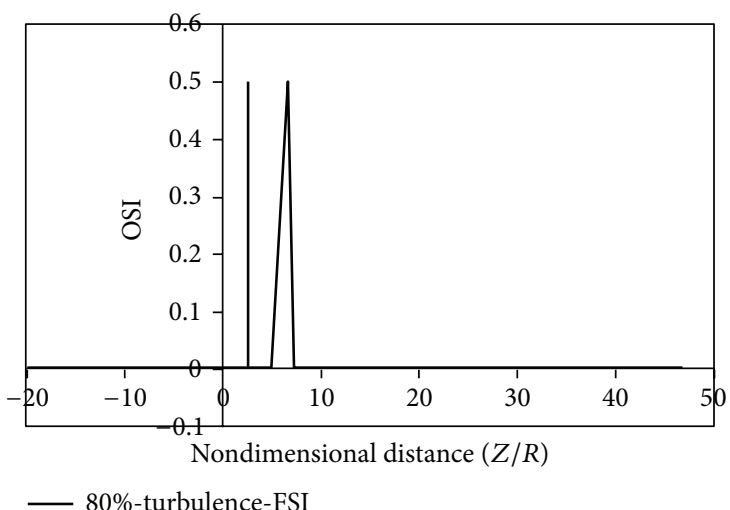

FIGURE 13: OSI, turbulence, flexible mode.

It can be seen from Figures 12 to 15 that there are two peaks for simple stenoses. In the simple stenosis, the first peak shows flow separation point and the second peak represents the reattachment point. Small values of timeaveraged shear stress and high values of the oscillatory shear index both influence the cell secretion resulting in increased cell displacement and increased dissociation of intercellular junctions thereby increasing permeability of the LDL particles to the wall [27-29]. The experimental 


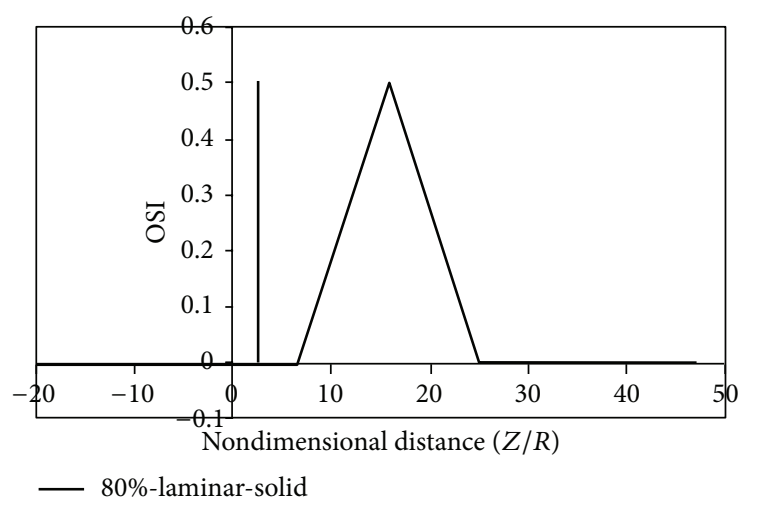

Figure 14: OSI, laminar, solid mode.

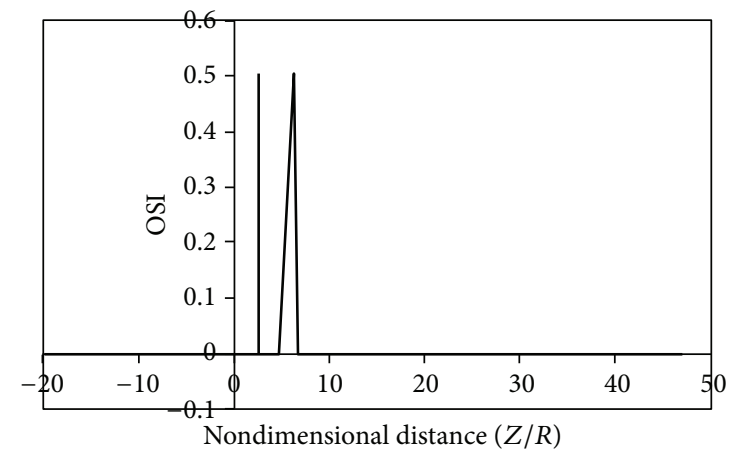

80\%-turbulence-solid

FIGURE 15: OSI, turbulence, solid mode.

results of Deng et al. [30] also show high absorption of cholesterol in the flow reattachment point. Another thing that can be seen in Figures 12 to 15 is that for both the rigid artery wall mode and the flexible artery wall mode, by changing the laminar flow assumption to the turbulent flow assumption, the length of oscillatory zone highly decreases. This shows that, in high percentages of stenosis when using any of hemodynamic parameters, average shear stress, and oscillatory shear index for describing how the disease is developed, failure to consider the turbulent flow behavior can cause a large numerical error.

Fry [31] stated that a shear stress over $40 \mathrm{~Pa}$ causes damage to endothelial cells. Ramstack et al. [32] stated that a shear stress greater than $100 \mathrm{~Pa}$ causes detachment of endothelial cells and clot formation. According to the contents of references [31,32] and Figures 8-11 it can be seen that, in $80 \%$ stenosis with the laminar flow assumption, the endothelial cell operation is damaged. However, in $80 \%$ stenosis assuming turbulent flow, given that the maximum stress is greater than $100 \mathrm{~Pa}$, the clot will form. Thus ignoring turbulence can make a different change in predicting damages. As can be seen in Figures 8 up to 15, the effect of turbulent flow on the maximum time-averaged shear stress of the wall on stenosis and the mean reverse flow area is more important than assuming flexible wall. The result that can be derived from Figure 16 is that the wall displacement with

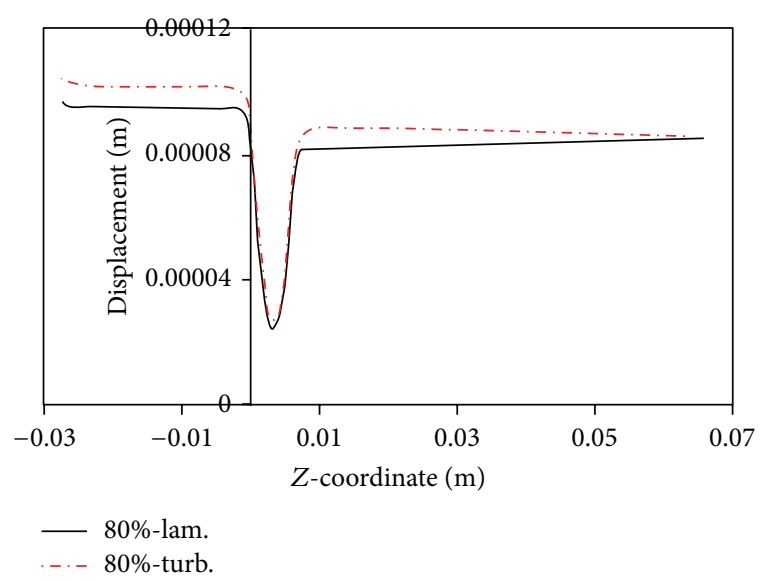

FIGURE 16: Radial displacement of wall at different mode.

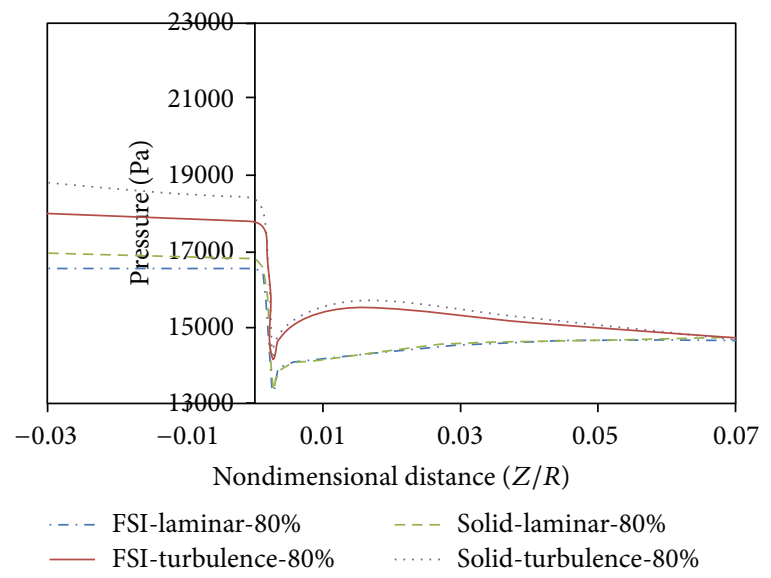

FIGURE 17: Changes in arterial pressure in the axial direction, $T_{2}$.

the turbulent flow assumption is more than the laminar flow assumption. Moreover, due to hypotension, the artery wall displacement in front of stenosis is more than the artery wall displacement at the back of stenoses.

Figure 17 shows changes in arterial pressure in the axial direction for simple stenosis with $80 \%$ stenosis at the maximum flow rate time. As can be seen from Figure 17, changing from flexible to rigid wall will increase the pressure in the proximal of stenosis. Moreover, changing from laminar to turbulent flow will increase the pressure in the proximal of stenosis. The hypotension in the turbulent mode is higher than the laminar mode and in the rigid wall artery mode higher than the flexible wall artery because of higher shear stress along the artery and consequently increased hypotension across the artery. Another result from Figure 17 is that, in front of the stenosis, the pressure difference at rigid and flexible modes is lower than at the back of stenosis. The reason is that, with decreasing pressure, the displacement of artery wall decreases and the artery wall becomes closer to the rigid mode.

Figures 18 to 20 compare changes in circumferential stresses in time at different points for $80 \%$ stenosis. As can be seen, compared to the turbulent flow assumption, 


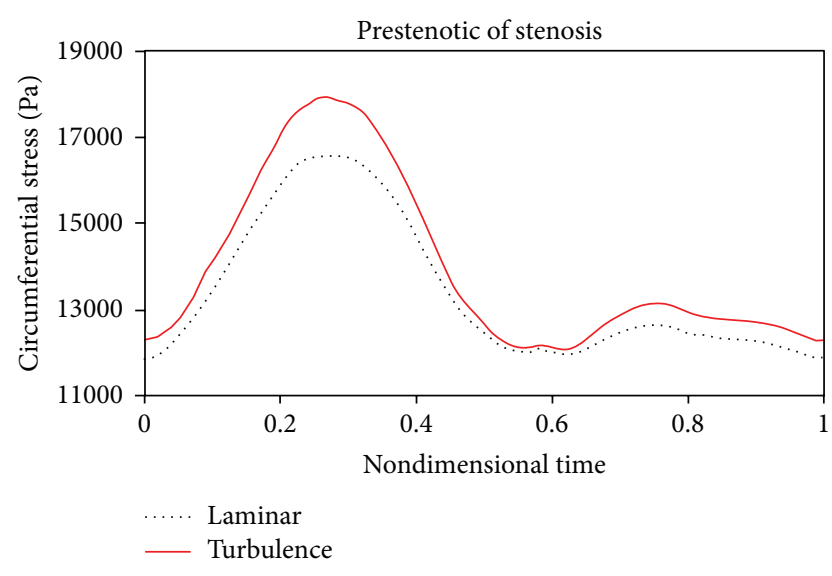

FIGURE 18: Circumferential stress, prestenotic.

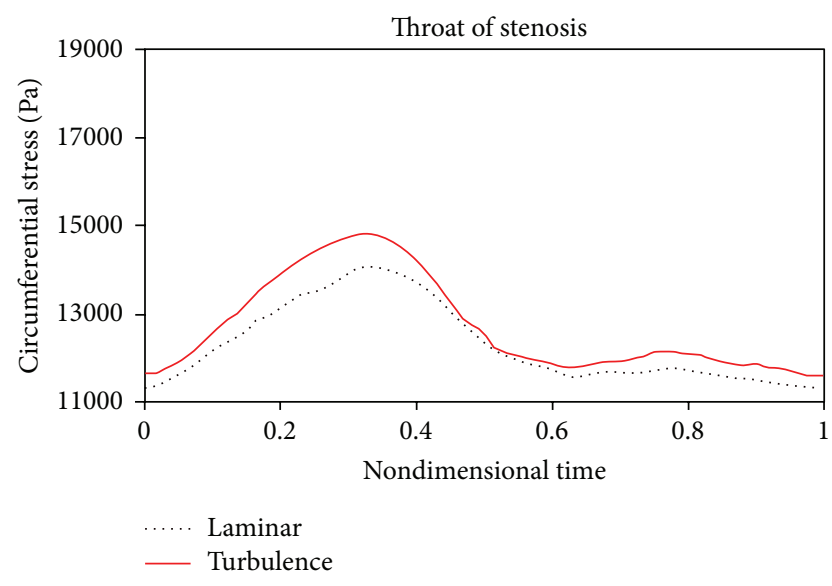

FIGURE 19: Circumferential stress, throat of stenosis.

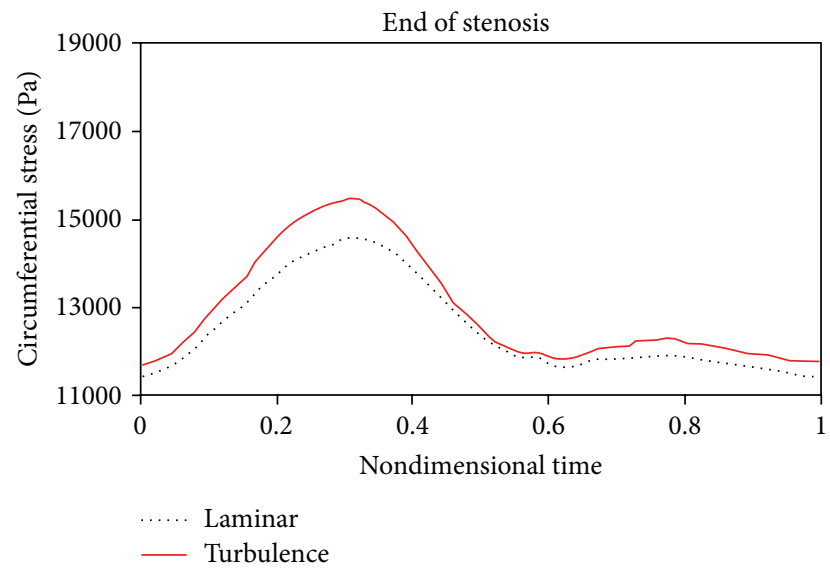

Figure 20: Circumferential stress, end of stenosis.

the laminar flow assumption shows lower circumferential stresses for the artery wall. The maximum circumferential stress is related to prestenotic zone because, according to Figure 17, the pressure exerted on the wall before the stenosis is higher. The minimum circumferential stresses are related to the stenosis peak because according to Figure 17, there is a

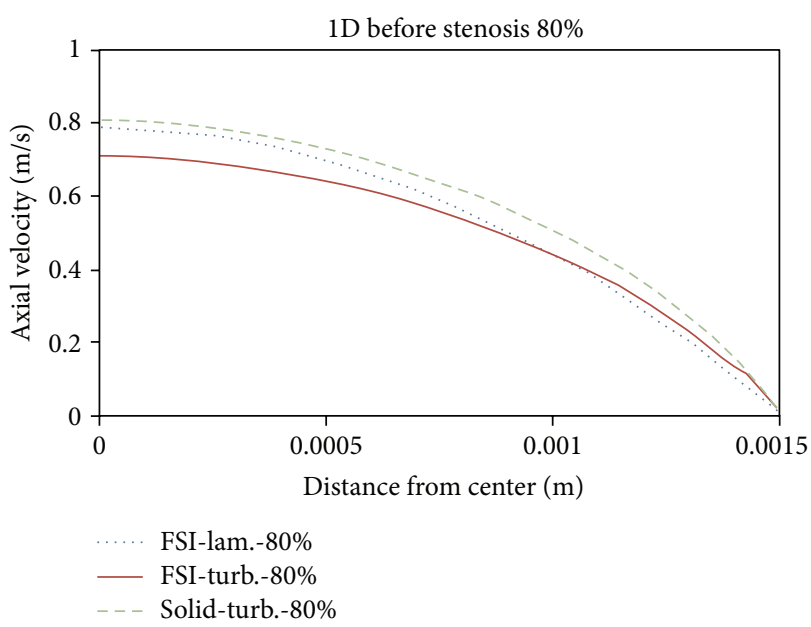

Figure 21: Axial velocity, 1D before stenosis.

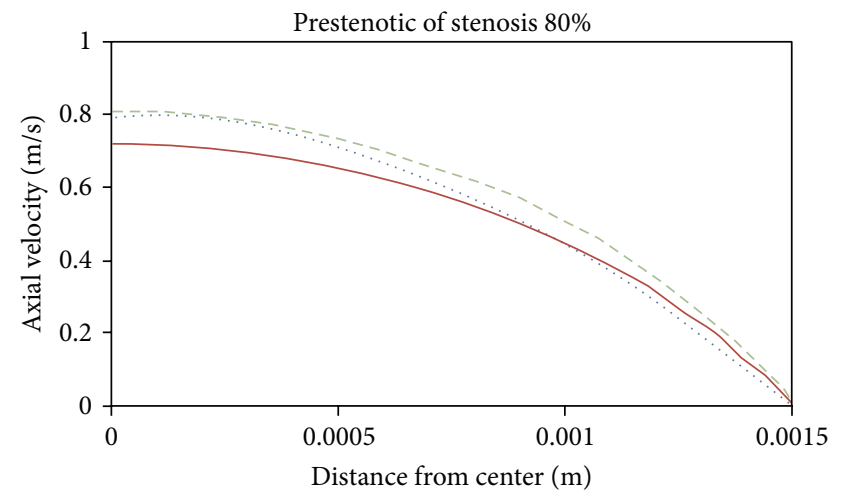

FSI-lam.-80\%

FSI-turb.- $80 \%$

Solid-turb.-80\%

FIgUre 22: Axial velocity, prestenotic of stenosis.

sudden pressure drop due to serious tweaking. Another result from Figures 18 to 20 is that the laminar flow assumption at the stenosis peak shows circumferential stress lower than the turbulent flow assumption.

Figures 21 to 24 show axial velocity profiles at the time of maximum flow rate $(0.24 \mathrm{~s})$, at a distance equal to the diameter before the stenosis, at the beginning of the stenosis, the throat, and the poststenotic of a simple $80 \%$ stenosis. Due to axial velocity profiles and also as expected the profile of turbulent flow assumption was obtained flatter than the laminar flow assumption, and the rigid wall mode further demonstrates maximum axial velocity. Figure 23 shows velocity profiles at the throat of the simple stenosis. It shows that the maximum velocity reaches a value much higher than $1 \mathrm{~m} / \mathrm{s}$. This value is beyond a normal biological mode and may cause disturbances in the blood circulatory system. Also, as can be seen in Figure 24, at the end of stenosis compared with the throat of the stenoses, the maximum velocity is reduced and both the laminar flow assumption and the turbulent flow assumption at near of the wall predict the reverse flow. 


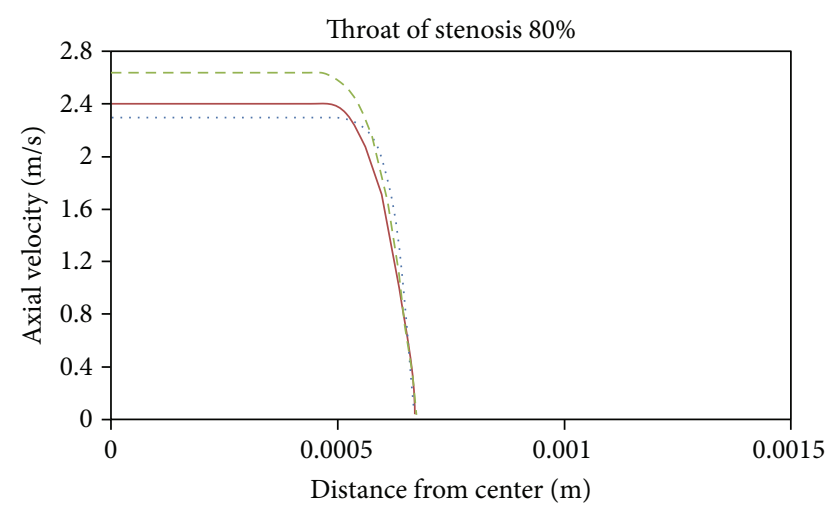

FSI-lam.-80\%

FSI-turb.- $80 \%$

- - - Solid-turb.- $80 \%$

FIGURE 23: Axial velocity, throat of stenosis.

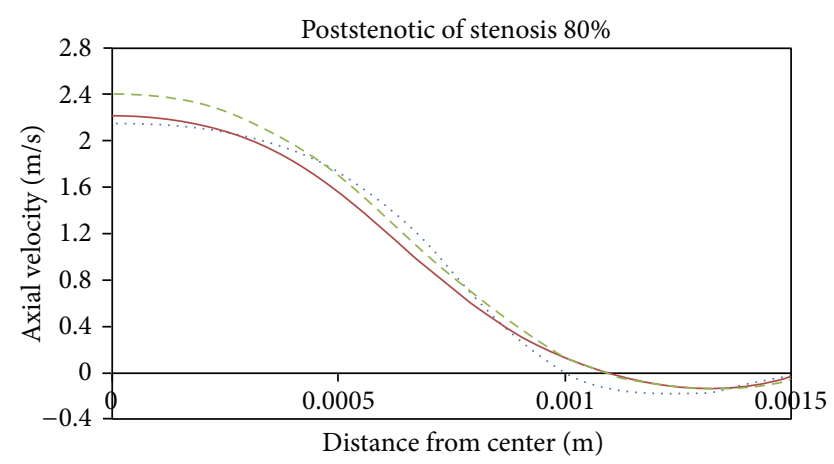

FSI-lam.- $80 \%$

— FSI-turb.-80\%

- - - Solid-turb.- $80 \%$

FIGURE 24: Axial velocity, poststenotic of stenosis.

However, the laminar flow overestimates the reverse flow and shows the reverse flow zone larger which is obvious because the fluid has a lower energy and is soon detached from the surface. In other words, using the laminar flow assumption a wider zone at the back of stenosis is exposed to the disease and using the turbulent flow assumption the growth speed of plaques is higher.

In Figures 25-28 distribution of pressure, shear stress at $T_{2}$ and $T_{4}$ and axial velocity along the artery are shown, respectively. As seen, minimum pressure and maximum axial velocity occurred in the throat of stenosis. In distal of stenosis by reducing the velocity, the pressure is increased and Figure 17 also showed this. By away from stenosis region and reducing the effects of narrowing and opening of the flow cross section, pressure is reduced linearly. Blood shear stresses that exerted from the artery wall are shown in Figures 26 and 27. Because of high similarity between turbulent and FSI case study contour by other case studies, contours of other cases have been ignored. At the narrowest of cross section it can be seen from Figure 26 that shear stress increased suddenly and immediately after stenosis throat reduced

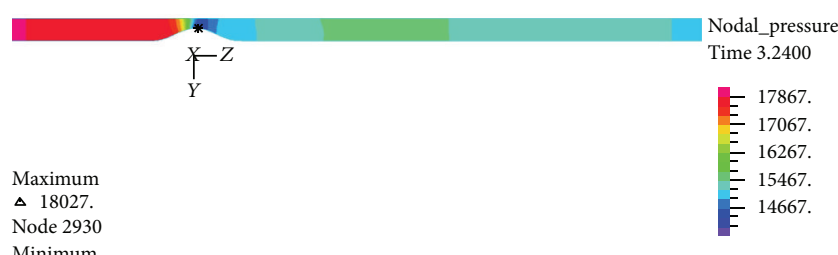

Minimum

* 14176

Node 3154

FIGURE 25: Pressure distribution at maximum flow rate $T_{2}$, FSI-Turb.

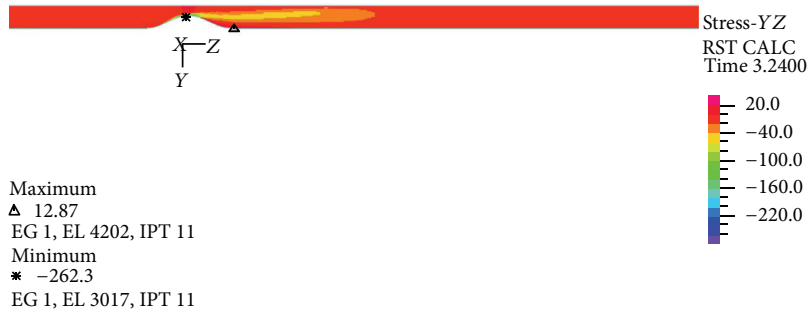

FIgURE 26: Shear stress distribution at maximum flow rate $T_{2}$, FSITurb.

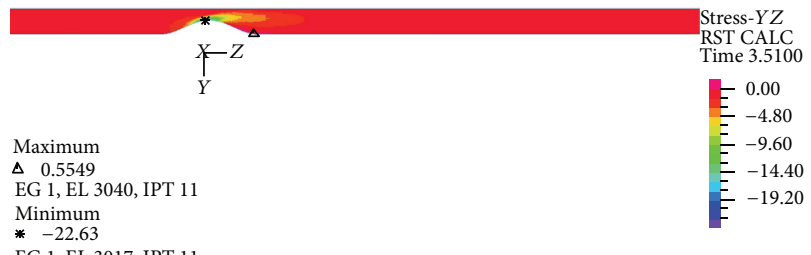

FIGURE 27: Shear stress distribution at minimum flow rate $T_{4}$, FSITurb.

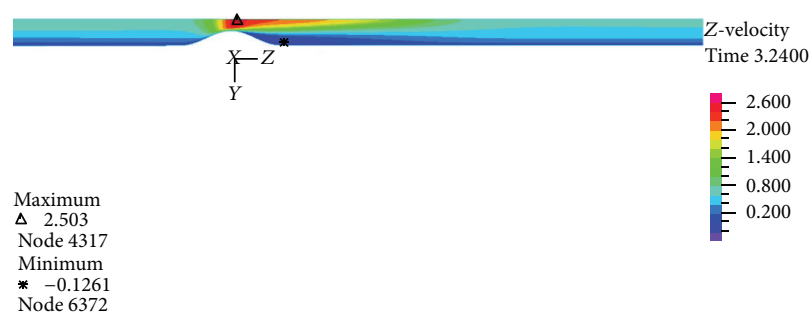

FIGURE 28: Velocity distribution at maximum flow rate $T_{2}$, FSI-Turb.

severely and even negative values are seen. Then shear stress in the reverse flow region increased by mild slope and again gives positive value and remains constant until the end of the artery. As can be seen from Figures 26 and 27 the difference between the shear stress on the artery wall at maximum and minimum flow rate is very high and almost 11.6 times and, at other times of the cardiac cycle, shear stress on the artery wall has continuous changes. These frequent changes on the inner surface of the artery can lead to plaque rupture that can cause severe cramping and formation and the development of blood clot in the arteries. According to Figure 28, minimum axial velocity is $-0.1261 \mathrm{~m} / \mathrm{s}$ and occurred at the end of stenosis and maximum axial velocity is $2.503 \mathrm{~m} / \mathrm{s}$ and occurred the throat of stenosis. 


\section{Conclusion}

Using ADINA software and taking into account the elastic wall and physiological pulses as a boundary condition, this paper assesses blood flow passing through the right coronary artery with a local stenosis. Compared with other numerical works, the $K-\varepsilon$ standard model had a better consistency with the experimental work and was better able to show the reverse flow region. We therefore used the $K-\varepsilon$ standard turbulence model to resolve the turbulent flow in the present numerical work. In the present work, the average inlet pressure for $80 \%$ stenosis in the laminar flow assumption was obtained 102.4 and at the turbulent flow assumption was obtained 105 compared with the other experimental works which was 104.8 . This indicates that, for $80 \%$ stenosis, the flow is turbulent. As a result, $80 \%$ stenosis was selected as the sample stenosis. The effects of turbulent blood flow were examined on pressure drop and velocity profiles. The obtained results were compared with those of the laminar flow assumption and the rigid coronary artery wall. For both the rigid artery wall and the flexible artery wall, by changing from the laminar flow assumption to the turbulent flow assumption, the length of oscillatory region becomes much lower. This shows that in high percentages of stenosis when using any of the hemodynamic parameters of the average shear stress and the oscillatory shear index for describing how the disease is spread, failure to consider the turbulent flow behavior can cause a large numerical error. Another result of the present work is that, in $80 \%$ stenosis, the rigid artery wall assumption makes a smaller error compared to the laminar blood flow assumption.

\section{Conflict of Interests}

The authors declare that there are no financial or personal relationships with people or organizations that have inappropriately influenced this work.

\section{References}

[1] V. Fuster, "Human lesion studies," Annals of the New York Academy of Sciences, vol. 811, no. 1, pp. 207-225, 1997.

[2] M. Tafazzoli, Analysis of mechanical stress in arteries with changes in wall structural properties [Ph.D. thesis], Graduate School of Biomedical Engineering, University of New South Wales, New South Wales, Australia, 1999.

[3] M. A. Zulligera, P. Frideza, K. Hayashib, and N. Stegiopulosa, "A strain energy function for arteries accounting for wall composition and structure," Journal of Biomechanics, vol. 37, no. 7, pp. 989-1000, 2004.

[4] T. Matsumoto, T. Goto, T. Furukawa, and M. Sato, "Residual stress and strain in the lamellar unit of the porcine aorta: experiment and analysis," Journal of Biomechanics, vol. 37, no. 6, pp. 807-815, 2004.

[5] W. Shyy, M. Francois, H. S. Udaykumar, N. N'dri, and R. Tran-Son-Tay, "Moving boundaries in micro-scale biofluid dynamics," Applied Mechanics Reviews, vol. 54, no. 5, pp. 405452, 2001

[6] X. Y. Xu, A. D. Augst, B. Ariff, and S. A. Thom, "Analysis of complex flow and its relationship with wall thickening in the carotid artery bifurcation," in Proceedings of the 11th International Conference on Computational Bioengineering, Lisbon, Portugal, September 2005.

[7] M. Bathe and R. D. Kamm, "A fluid-structure interaction finite element analysis of pulsatile blood flow through a compliant stenotic artery," Journal of Biomechanical Engineering, vol. 121, no. 4, pp. 361-369, 1999.

[8] D. Tang, C. Yang, and D. N. Ku, "A 3-D thin-wall model with fluid-structure interactions for blood flow in carotid arteries with symmetric and asymmetric stenoses," Computers and Structures, vol. 72, no. 1-3, pp. 357-377, 1999.

[9] L. Wei, Numerical study of steady and pulsatile flow through stenosed tubes [Ph.D. thesis], Department of Mechanical Engineering, National University of Singapore, Singapore, 2004.

[10] R. Mittal, S. P. Simmons, and H. S. Udaykumar, "Application of large-eddy simulation to the study of pulsatile flow in a modeled arterial stenosis," Journal of Biomechanical Engineering, vol. 123, no. 4, pp. 325-332, 2001.

[11] M. R. Roach, "Poststenotic dilatation in arteries," Cardiovascular Fluid Dynamics, vol. 2, pp. 111-139, 1972.

[12] C. Clark, "Turbulent velocity measurements in a model of aortic stenosis," Journal of Biomechanics, vol. 9, no. 11, pp. 677-687, 1976.

[13] M. D. Deshpande and D. P. Giddens, "Turbulence measurements in a constricted tube," Journal of Fluid Mechanics, vol. 97, no. 1, pp. 65-89, 1980.

[14] S. A. Ahmed and D. P. Giddens, "Velocity measurements in steady flow through axisymmetric stenoses at moderate Reynolds numbers," Journal of Biomechanics, vol. 16, no. 7, pp. 505-516, 1983.

[15] S. A. Ahmed and D. P. Giddens, "Pulsatile poststenotic flow studies with laser Doppler anemometry," Journal of Biomechanics, vol. 17, no. 9, pp. 695-705, 1984.

[16] F. Ghalichi, X. Deng, A. De Champlain, Y. Douville, M. King, and R. Guidoin, "Low Reynolds number turbulence modeling of blood flow in arterial stenoses," Biorheology, vol. 35, no. 4-5, pp. 281-294, 1998.

[17] J. Banks and N. W. Bressloff, "Turbulence modeling in threedimensional stenosed arterial bifurcations," Journal of Biomechanical Engineering, vol. 129, no. 1, pp. 40-50, 2007.

[18] ADINA R\&D, Theory and Modeling Guide, Volume III: ADINA CFD \& FSI, Help of ADINA Software, ADINA R\&D, 2011.

[19] S. S. Varghese and S. H. Frankel, "Numerical modeling of pulsatile turbulent flow in stenotic vessels," Journal of Biomechanical Engineering, vol. 125, no. 4, pp. 445-460, 2003.

[20] D. Zeng, E. Boutsianis, M. Ammann, K. Boomsma, S. Wildermuth, and D. Poulikakos, "A study on the compliance of a right coronary artery and its impact on wall shear stress," Journal of Biomechanical Engineering, vol. 130, no. 4, Article ID 041014, 2008.

[21] M. R. Sadeghi, E. Shirani, M. Tafazzoli-Shadpour, and M. Samaee, "The effects of stenosis severity on the hemodynamic parameters-assessment of the correlation between stress phase angle and wall shear stress," Journal of Biomechanics, vol. 44, no. 15, pp. 2614-2626, 2011.

[22] J. V. Soulis, O. P. Lampri, D. K. Fytanidis, and G. D. Giannoglou, "Relative residence time and oscillatory shear index of nonnewtonian flow models in aorta," in Proceedings of the 10th International Workshop on Biomedical Engineering, pp. 1-4, Kos, Greece, October 2011. 
[23] M. Gawaz, "Role of platelets in coronary thrombosis and reperfusion of ischemic myocardium," Cardiovascular Research, vol. 61, no. 3, pp. 498-511, 2004.

[24] H. S. Bassiouny, R. H. Song, X. F. Hong, A. Singh, H. Kocharyan, and S. Glagov, "Flow regulation of 72-kD collagenase IV (MMP2) after experimental arterial injury," Circulation, vol. 98, no. 2, pp. 157-163, 1998.

[25] M. T. Dirksen, A. C. van der Wal, F. M. van den Berg, C. M. van der Loos, and A. E. Becker, "Distribution of inflammatory cells in atherosclerotic plaques relates to the direction of flow," Circulation, vol. 98, no. 19, pp. 2000-2003, 1998.

[26] Ö. Smedby, "Do plaques grow upstream or downstream? An angiographic study in the femoral artery," Arteriosclerosis, Thrombosis, and Vascular Biology, vol. 17, no. 5, pp. 912-918, 1997.

[27] D. N. Ku, D. P. Giddens, C. K. Zarins, and S. Glagov, "Pulsatile flow and atherosclerosis in the human carotid bifurcation. Positive correlation between plaque location and low oscillating shear stress," Arteriosclerosis, Thrombosis, and Vascular Biology, vol. 5, no. 3, pp. 293-302, 1985.

[28] T. Kadohama, K. Nishimura, Y. Hoshino, T. Sasajima, and B. E. Sumpio, "Effects of different types of fluid shear stress on endothelial cell proliferation and survival," Journal of Cellular Physiology, vol. 212, no. 1, pp. 244-251, 2007.

[29] U. Olgac, V. Kurtcuoglu, and D. Poulikakos, "Computational modeling of coupled blood-wall mass transport of LDL: effects of local wall shear stress," The American Journal of PhysiologyHeart and Circulatory Physiology, vol. 294, no. 2, pp. H909H919, 2008.

[30] X. Deng, Y. Marois, M. W. King, and R. Guidoin, "Uptake of $3 \mathrm{H}-7$-cholesterol along the arterial wall at an area of stenosis," ASAIO Journal, vol. 40, no. 2, pp. 186-191, 1994.

[31] D. L. Fry, "Acute vascular endothelial changes associated with increased blood velocity gradients," Circulation Research, vol. 22, no. 2, pp. 165-197, 1968.

[32] J. M. Ramstack, L. Zuckerman, and L. F. Mockros, "Shearinduced activation of platelets," Journal of Biomechanics, vol. 12, no. 2, pp. 113-125, 1979. 


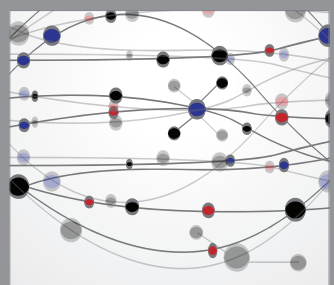

The Scientific World Journal
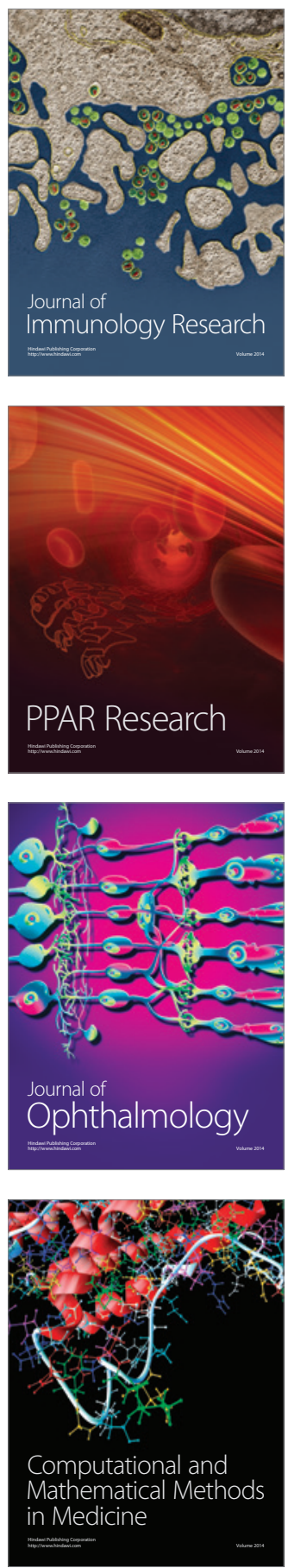

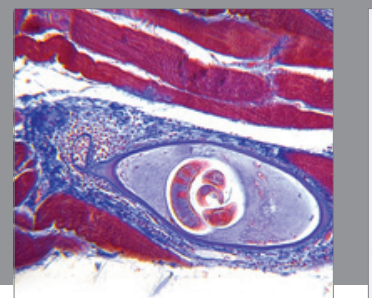

Gastroenterology

Research and Practice
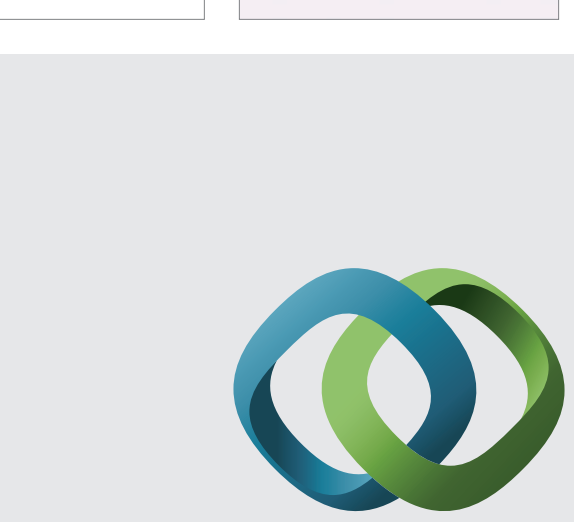

\section{Hindawi}

Submit your manuscripts at

http://www.hindawi.com
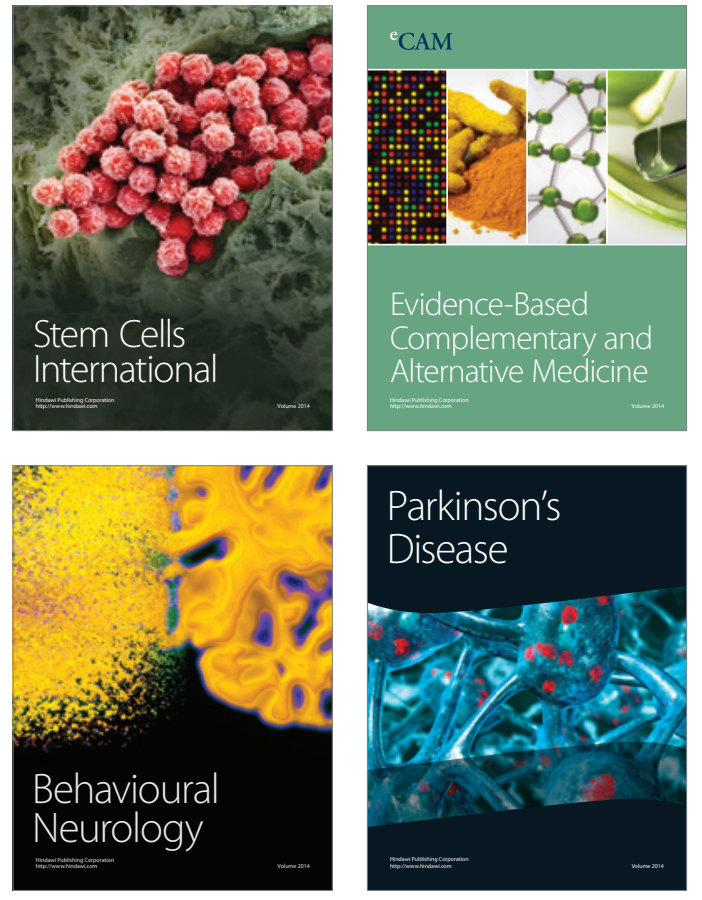
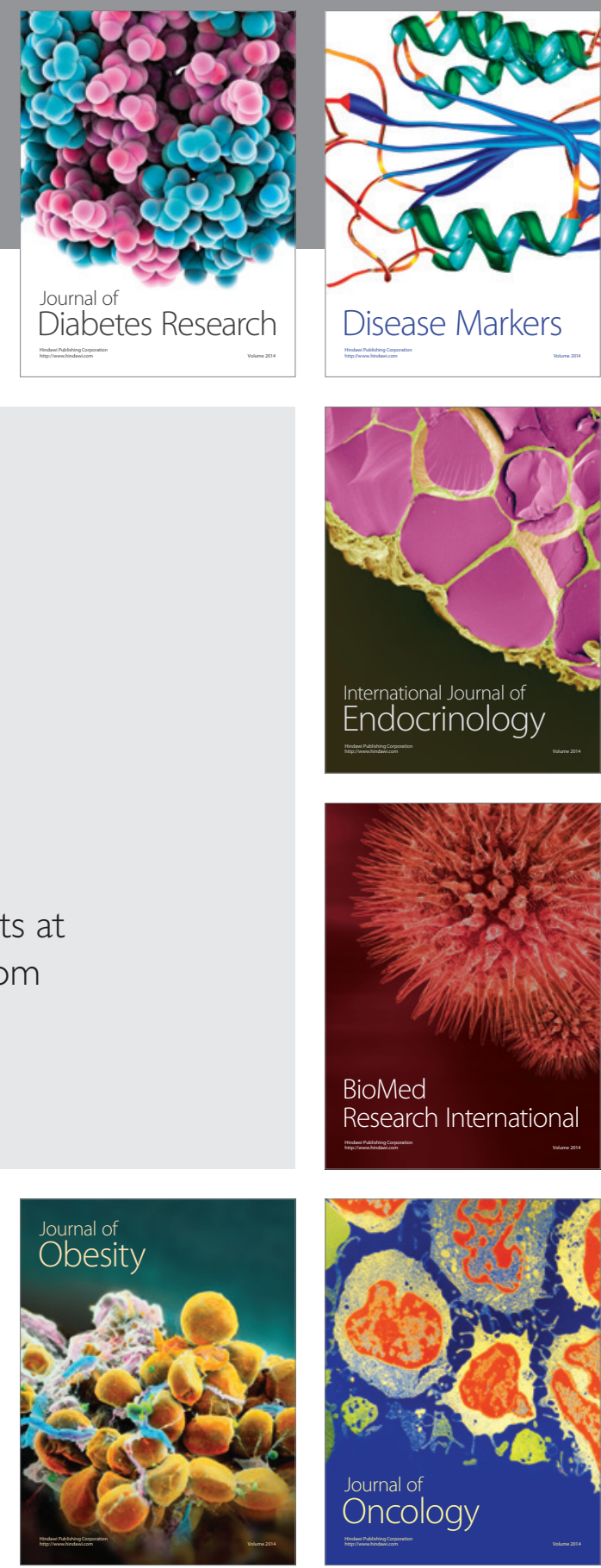

Disease Markers
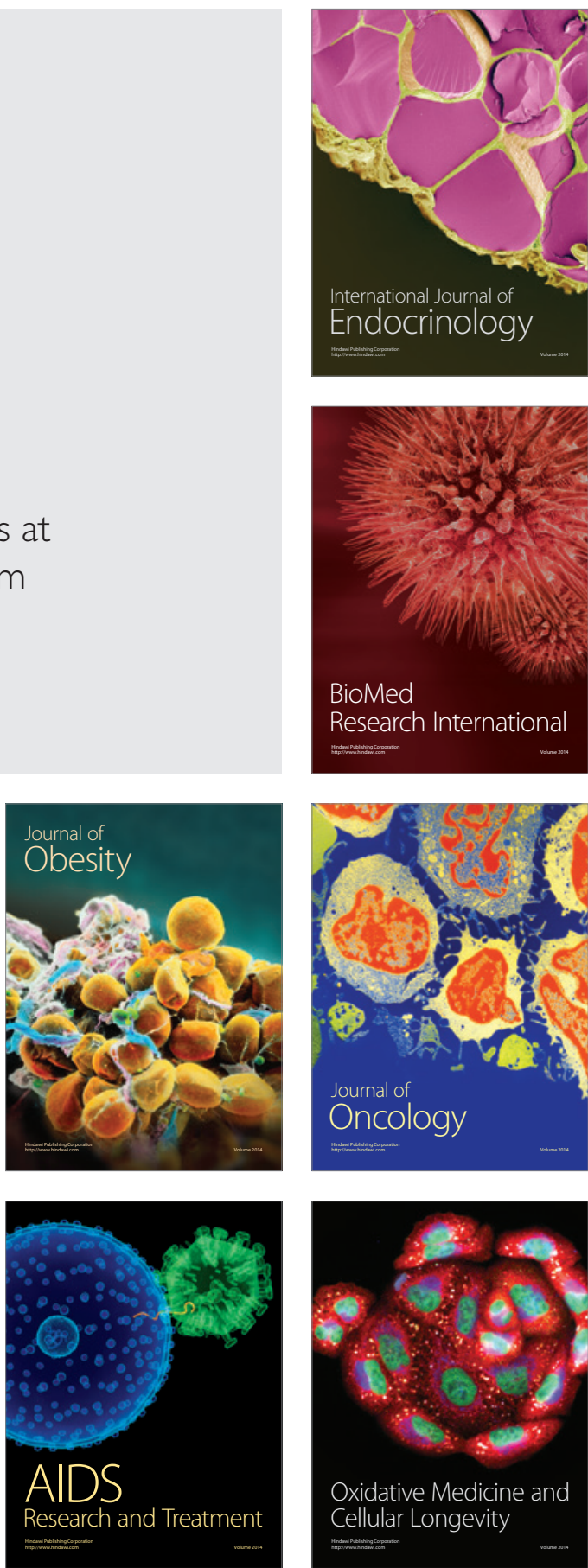